\title{
PROTESTANTISMO BRASILEIRO CONTEMPORÂNEO: EVIDÊNCIAS BÍBLICAS EM CONTRAPONTO À PROSPERIDADE APRESENTADA PELO NEOPENTECOSTALISMO
}

\section{ARTIGO ORIGINAL}

CUNHA, David Carvalho ${ }^{1}$

CUNHA, David Carvalho. Protestantismo brasileiro contemporâneo: Evidências bíblicas em contraponto à prosperidade apresentada pelo neopentecostalismo. Revista Científica Multidisciplinar Núcleo do Conhecimento. Ano 05, Ed. 06, Vol. 10, pp. 146-157. Junho de 2020. ISSN: 2448-0959, Link de acesso: https://www.nucleodoconhecimento.com.br/teologia/protestantismobrasileiro

\section{RESUMO}

Devido a formatação das suas principais crenças religiosas, o neopentecostalismo tem trazido, direta e indiretamente, representatividade à fé de grande parte dos cristãos protestantes no Brasil. Entretanto, a ênfase em algumas dessas crenças quando postas em prática tem causado discordâncias e debates entre os demais cristãos, principalmente quanto ao quesito prosperidade. Dessa maneira, surge o seguinte questionamento: quanto à prosperidade material, quais as principais diferenças entre as práticas da igreja primitiva, contextualizada no período do primeiro século, e as práticas das igrejas neopentecostais? O presente estudo tem como objetivo descrever as principais igrejas neopentecostais, identificar as suas principais crenças e erros doutrinários quanto à prosperidade bíblica e contrapor essa doutrinação, que tem tido o maior foco nas suas reuniões, com as verdades bíblicas que foram ensinadas e praticadas pelos primeiros cristãos. Foi realizada, para tanto,

1 Graduado em Engenharia com ênfase em eletrônica (CEFET-RJ); Seminário teológico interconfessional (Uninter); Pós-graduação em Capelania (Faveni); Pósgraduação em História das Religiões (Faveni). 
uma pesquisa bibliográfica a fim de se discutir sobre o assunto. Na conclusiva, destaca-se a ênfase exagerada à prosperidade material como o maior desvio teológico do neopentecostalismo, sendo, então, ressignificado esse conceito e apresentadas as refutações bíblicas pertinentes como evidências para as devidas restaurações doutrinárias.

Palavras-chave: Neopentecostalismo, Igreja primitiva, prosperidade material, verdades bíblicas.

\section{INTRODUÇÃO}

O contexto mundial que perpassou o século XIX destaca-se em razão de um acontecimento marcante: as revoluções econômica, social, política, tecnológica e religiosa. Com isso, é preciso destacar, nessa reflexão, que a humanidade estava experimentando avanços científicos e novas descobertas espirituais. De fato, esse foi o grande século da expansão missionária para o cristianismo, o que torna relevante a sua menção. Porém, em meio a influência do iluminismo, a racionalização do pensamento humano em contraponto a fé, juntamente com essas descobertas e avanços tecnológicos, o cristianismo passou a enfrentar um poderoso inimigo interno: o liberalismo teológico. Nesse momento, surge o pentecostalismo, talvez como uma grande resposta ou convite divino quanto ao combate à esse esfriamento espiritual.

Acredita-se, portanto, que é preciso viver experiências verdadeiras com o Senhor a partir do Espírito Santo, como os apóstolos viveram em pentecostes (uma das três principais festas anuais de Israel cujo segundo capítulo do livro bíblico dos Atos dos Apóstolos descreve a comemoração dessa festa após a morte e ressurreição de Cristo. Essa ocasião apresenta a descida do Espírito Santo sobre os discípulos de Jesus). Foi o marco inicial desse movimento, o que certamente o caracteriza como verdadeiro. Derivando diretamente do pentecostalismo, surge, no contexto religioso brasileiro, o novo pentecostalismo ou neopentecostalismo, num momento em que a variedade cultural representava um fator determinante à construção das crenças, rituais e costumes que modelavam a característica mais marcante da religiosidade brasileira: o misticismo. 
Considerando o contexto apresentado é preciso mencionar que, de certa forma, a influência mística presente no pensamento cotidiano do povo brasileiro, e, também, em suas ações, alcançou espaço também dentro desse movimento, orientando-o em direção a crenças estranhas e a práticas distorcidas. Sendo assim, o contexto teológico em que as igrejas neopentecostais se encontram revelam a necessidade de uma reflexão crítica em busca da verdade que as possa conduzir ao retorno a essência do evangelho de Cristo. Logo, o grande dilema repousa em qual seria a principal diferença teológica entre a igreja primitiva e as igrejas neopentecostais, e, ainda, cabe a reflexão acerca de quais as refutações necessárias para a solução desse erro doutrinário. Pensar em tais distinções justifica a relevância do presente estudo.

Este estudo tem o objetivo de apresentar as principais denominações do movimento neopentecostal brasileiro, identificar suas principais crenças e incoerências doutrinárias quanto à prosperidade material, questão que tem tido o maior foco nas liturgias, contrapor esse pensamento teológico com as verdades bíblicas de forma a evidenciar o ensino e refletir sobre a prática dos cristãos da igreja do primeiro século. O método empregado na pesquisa foi o bibliográfico, utilizando-se de livros e sites eletrônicos como base para a obtenção dos elementos históricos, para o mapeamento das liturgias e costumes, para a coleta de informações, e, ainda, foi utilizada a Bíblia Sagrada como fonte para a construção dos princípios necessários para as devidas refutações, sendo, também, destacados alguns exemplos práticos dos primeiros cristãos da história.

\section{DESENVOLVIMENTO}

Segundo Freston (1993), o pentecostalismo brasileiro pode ser compreendido mediante a implantação de igrejas específicas no século passado, em três momentos diferentes (Pentecostalismo, Deuteropentecostalismo e Neopentecostalismo). primeiro momento durou cerca de quarenta anos e foi marcado pela ênfase no dom de línguas (conforme descrito nos livros de Marcos 16:17 e Atos 2:4), iniciando-se com a Congregação Cristã, fundada em 1910, em São Paulo, e a Assembleia de Deus em 1911, no Pará. O segundo momento compreende as décadas de 50 e 60 e foi 
marcado pela ênfase no dom de cura (conforme os livros de Marcos 16:18 e I Coríntios 12:9), tendo como principais protagonistas as igrejas Quadrangular, fundada em 1951, São Paulo, Brasil para Cristo em 1955, São Paulo, Deus é Amor em 1962, São Paulo e Casa da Bênção em 1964, Minas Gerais.

O terceiro momento iniciou-se na década de 70, com a fundação da Igreja Universal do Reino de Deus (IURD) em 1977 e da Igreja Internacional da Graça de Deus (IIGD) em 1980, ambas no Rio de Janeiro, e, posteriormente, com a formação de outras igrejas de menor expressão. Silva (2007) informa que à essa terceira onda do movimento pentecostal brasileiro acresceu-se o prefixo "neo", ficando conhecida como movimento neopentecostal, pretendendo diferenciar essas novas igrejas com base nas suas novas práticas, crenças e perfis. César (2000) apresenta uma relação detalhada descrevendo setenta e nove igrejas oriundas das três ondas do movimento pentecostal. Os dados do IBGE de 2010[2] mostram os evangélicos pentecostais/neopentecostais dentro do cenário religioso brasileiro como sendo o segundo maior grupo do país.

Logo, demonstra-se a relevância desse movimento para o cristianismo brasileiro. Porém, é necessário um estudo para averiguar a veracidade das crenças neopentecostais.

\subsection{PRINCIPAIS IGREJAS NEOPENTECOSTAIS}

\subsubsection{IGREJA UNIVERSAL DO REINO DE DEUS}

A primeira IURD foi erguida em uma antiga funerária, na Abolição, cidade do Rio de janeiro, e o primeiro culto foi realizado em 09/07/1977, conforme relatado no seu site oficial[3]. César (2000) complementa dizendo que Edir Macedo se converteu na Igreja de Nova Vida, em Botafogo, também cidade do Rio de Janeiro, e, por questões não reveladas, algum tempo depois saiu dessa igreja com o seu cunhado Romildo Ribeiro Soares, conhecido R. R. Soares, fundando ambos a IURD. 


\subsubsection{IGREJA INTERNACIONAL DA GRAÇA DE DEUS}

César (2000) relata que devido a diferenças teológicas pouco tempo após a fundação da IURD, R. R. Soares separou-se de Macedo e fundou a IIGD, em nove de junho de mil novecentos e oitenta. O site oficial da IIGD[4] informa que R. R. Soares foi o primeiro a falar de Cristo em horário nobre na televisão brasileira a partir do programa Show da Fé.

\subsubsection{IGREJA MUNDIAL DO PODER DE DEUS}

A história da fundação da Igreja Mundial do Poder de Deus (IMPD) está descrita no seu site oficial[5] e diz que após receber grande livramento durante um acidente em Moçambique, na África, com o navio que o deixou durante horas em alto mar, Valdomiro Santiago voltou ao Brasil e fundou a IMPD em três de março de mil novecentos e noventa e oito. A igreja preocupa-se em mostrar Jesus Cristo como vivo e presente, e, por isso, declara que sinais sobrenaturais seguirão aos que crerem (conforme descrito no livro de Marcos 16:17 e 18).

\subsubsection{IGREJA APOSTÓLICA PLENITUDE DO TRONO DE DEUS}

Conforme relatado pela Revista Ancora[6], Agenor Duque teve significativa passagem pela IURD e IMPD, sendo um dos seus principais pastores. Após deixar essas denominações em setembro de 2006, Duque inaugurou a Igreja Apostólica Plenitude do Trono de Deus (IAPTD), que, em menos de dez anos, já possuía considerável espaço no cenário religioso nacional a partir de programas de rádio e TV.

\subsubsection{OUTRAS IGREJAS}

Os atuais, apóstolo Estevam e bispa Sônia Hernandes, ao deixarem a igreja em que faziam parte, conforme relatado no site oficial da Igreja Renascer em Cristo[7], passaram a realizar cultos em seu apartamento no ano de 1985. Em pouco tempo, com o aumento dos participantes, utilizaram alguns salões, até que em doze de março de mil novecentos e oitenta e seus inauguraram oficialmente a Igreja Renascer em 
Cristo na Avenida Lins de Vasconcelos, São Paulo. A Renascer enfatiza a prosperidade material na vida cristã e o ministério de louvor. O site oficial da Igreja Sara Nossa Terra[8] descreve que em 1992 o casal Robson e Maria Lúcia Rodovalho iniciaram trabalhos por meio de células. Em 1994 inauguraram a Igreja Sara Nossa Terra no Setor Sudoeste de Brasília. Atualmente a igreja possui emissora e retransmissoras de TV, rádios, editora e gravadora gospel. Ainda, outras dezenas de igrejas e comunidades evangélicas com vertentes neopentecostais e de menor expressão nasceram entre os anos de 1980 e 2000.

\subsection{PRINCIPAIS PRÁTICAS NEOPENTECOSTAIS}

As práticas e crenças adotadas por esse movimento diferenciam e definem a terceira onda pentecostal das demais. A revista USP (2005), discorrendo sobre este tema, destaca como principais características adotadas pelo movimento neopentecostal a tentativa de abandono do ascetismo religioso, a valorização do pragmatismo, a teologia da prosperidade, o trabalho de proselitismo em massa, a teologia da batalha espiritual com foco nas religiões afro-brasileiras e no espiritismo etc. O XI Simpósio Nacional da Associação Brasileira de História das Religiões[9] destacou a Teologia da Prosperidade e a Teologia da Batalha Espiritual como as duas principais doutrinas que representam o neopentecostalismo brasileiro, sendo ambas desenvolvidas por movimentos nascidos no exterior. Este estudo se voltará às questões mais polêmicas relacionadas à prosperidade na vida do cristão, apresentando exemplos práticos e a essência do pensamento dos primeiros cristãos como devida refutação.

\subsubsection{TEOLOGIA DA PROSPERIDADE}

A teologia da prosperidade apresenta, ao cristão, princípios bíblicos para uma vida terrena próspera em todos os sentidos, ou seja, em termos material e financeiro, espiritual e psicológico, envolvendo a sua saúde e suas emoções etc. Keneth Erwin Hagin liderou esse movimento doutrinário nos Estados Unidos nos anos setenta do século passado. Gondim (1993) reitera que Hagin teria se convertido após passar pelo abandono do pai, problemas clínicos da mãe e, também, em razão de uma saúde debilitada desde a infância. Então, por volta dos dezesseis anos, ele teria 
experimentado algumas experiências espirituais fora do corpo, como visitas ao céu e ao inferno que o impulsionaram a conversão e ao estudo bíblico. Tem-se como foco as reflexões de Marcos 11:23 e 24 ("porque em verdade vos afirmo que, se alguém disser a este monte: Ergue-te e lança-te no mar, e não duvidar no seu coração, mas crer que se fará o que diz, assim será com ele. Por isso, vos digo que tudo quanto em oração pedirdes, crede que recebestes, e será assim convosco").

Hagin descobre o segredo que proporcionou a sua cura e a grande ênfase do seu ministério: "creia no seu coração, decrete com sua boca e será vosso". Nesse sentido, o estudo de Mariano (1996) descreve, também, Kenneth Copeland, Oral Roberts, Robert Schuller, Jerry Falwell, T. L. Osborn, Charles Capps, Benny Hinn, Pat Robertson, Paul Crouch e Fred Price como os principais propagadores da teologia da prosperidade. No Brasil, a teologia da prosperidade foi adotada como regra pela liderança das igrejas neopentecostais e por muitas igrejas pentecostais, sendo este assunto uma das grandes estratégias motivacionais de atração do público para as suas reuniões e tendo, tornando-se, também, uma das partes mais relevantes na liturgia dos seus cultos. Visando apresentar a teologia da prosperidade de forma mais sistemática, esta será definida a partir de dois tópicos correspondentes a confissão positiva, determinismo ou poder da palavra e a materialização da fé.

\subsubsection{CONFISSÃO POSITIVA (O PODER DA PALAVRA)}

Representa o ensinamento de que a palavra falada (do grego rhema) deva ser colocada em prática por meio da fé. Araújo (2007, pp. 616 e 617), diz que "a fé é uma confissão", logo "o que eu confesso, eu possuo", ou ainda, que a confissão "cria realidades com as palavras proferidas pela boca”. O determinismo ou a ousadia em exercer o poder que há em uma palavra declarada é uma das maiores características do movimento neopentecostal. Assim, cabe destacar que:

- "Você é quem determina sua vitória: Determinei que, se eu fosse abraçada pelo homem de Deus, eu seria curada", diz um testemunho no site oficial da IMPD[10], onde é relatada a história de uma senhora angolana que ao 
determinar pela fé vir ao Brasil e receber um abraço do apóstolo Valdomiro seria curada.

- "Vou provar pra ele que maior do que a incredulidade dele é a minha fé", declarou o apóstolo Agenor Duque[11] durante uma campanha denominada "Milagre de Manassés", onde a memória de um homem viciado em álcool teria sido apagada e este liberto do vício.

O site oficial da IIGD[12] motiva os fiéis a praticarem a doutrina da determinação, ou seja, as bênçãos não devem ser pedidas a Deus, mas reivindicadas.

\subsubsection{MATERIALIZAÇÃO DA FÉ}

Outra prática essencial no meio neopentecostal é o incentivo à "materialização" da fé, ou seja, os fiéis são encorajados a depositar suas expectativas em campanhas milagrosas, objetos ungidos, jejuns poderosos etc. Quanto às campanhas milagrosas, a IIGD relata o seguinte testemunho em seu site oficial[13]:

Em 2006, minha filha estava com problemas de notas na faculdade. Sempre que orava por ela, vinha à minha mente o versículo: "Buscai em primeiro lugar o reino de Deus e a sua Justiça (...)". Em uma noite, após orar, liguei a TV no programa Show da Fé. O referido versículo estava na tela, e o Missionário disse: "Minha irmã, a sua filha está em dificuldades? O que você está esperando para inscrevê-la como patrocinadora?". Imediatamente a inscrevi, e ela conseguiu ser aprovada, para a glória de Deus. Amo Jesus.

A IURD, em seu site oficial[14], relata o testemunho do sucesso de uma fiel que participou da "Fogueira Santa de Israel", decidindo estipular o salário que seu marido passaria a receber a partir do valor equivalente depositado no altar da igreja, sendo abençoada em pouco tempo depois com exatamente a quantia sugerida. Em 2009 o pastor Silas Malafaia recebeu o pastor Morris Cerullo no Rio de Janeiro para participação especial em seu programa de televisão, Vitória em Cristo[15]. Na ocasião, o pastor Cerullo apresentou um ousado desafio aos fiéis alegando que Deus mudaria 
a história dos negócios e posições sociais daqueles que realizassem uma considerável doação de $\mathrm{R} \$ 911,00$.

Quanto à utilização de objetos como ajuda na materialização da fé, a IIGD[16] relata que um dos seus fiéis havia recebido a cura do vício do cigarro após colocar um copo d'água em cima da TV e receber orações. Quanto à prática do jejum, a IURD[17] tem por costume convocar os fiéis para o "Jejum das causas impossíveis", realizado todos os sábados. Declara que somente por meio de um jejum focado em situações impossíveis é que a solução surgirá.

\subsection{REFUTAÇÃO BÍBLICA}

Toda teoria religiosa precisa estar alicerçada em fundamentos que sejam suficientes para a aprovação dos seus ritos e práticas. No caso do cristianismo, a Bíblia sagrada corresponde à autoridade máxima que respalda as suas convicções e práticas da fé. O apóstolo Paulo declara que: "[...] a fé vem pela pregação, e a pregação, pela palavra de Cristo." (BÍBLIA, Romanos, 10:17). E, ainda: "toda Escritura é inspirada por Deus e útil para o ensino, para a repreensão, para a correção, para a educação na justiça." (BÍBLIA, 2 Timóteo, 3:16). Então, Deus entregou ao homem a Sagrada Escritura como fonte para revelação da sua vontade. Gonzalez (2004, p. 27) afirma que: "[...] a Palavra de Deus (que é a Verdade) é capaz de confrontar a igreja com uma demanda por absoluta obediência [...]".

Por isso, todo princípio doutrinário desenvolvido ao longo da história da igreja precisou necessariamente estar fundamentado na Bíblia, que é a expressão maior da vontade de Deus para o homem. Uma vez esclarecido que toda teologia cristã precisa encontrar suporte na Palavra de Deus, podemos argumentar que no livro bíblico dos atos dos apóstolos são apresentadas quatro práticas que contribuíram significativamente para o crescimento da igreja primitiva: "E perseveravam na doutrina dos apóstolos e na comunhão, no partir do pão e nas orações" (BÍBLIA, Atos, 2:42, grifo nosso), e, como consequência: "Da multidão dos que creram era um o coração e a alma. Ninguém considerava exclusivamente sua nem uma das 
coisas que possuía; tudo, porém, Ihes era comum" (BÍBLIA, Atos, 4:32, grifo nosso).

Sendo assim, cabem as seguintes reflexões: na perspectiva da igreja do primeiro século, qual o método utilizado para que não houvesse necessidades quaisquer entre os irmãos? E, no contexto contemporâneo neopentecostal, uma vez que existam ricos e pobres nas igrejas, como são combatidas essas desigualdades sociais extremas? Quem deveria ser o verdadeiro responsável pela provisão das bênçãos financeiras entre o povo que cresse, Deus ou a própria igreja? Essas simples reflexões, quando vistas a partir dos óculos da igreja primitiva, sem dúvida nos levam a inevitável conclusão de que a "Teologia da Prosperidade" aplicada ao contexto do primeiro século da igreja representaria o uso da fé necessariamente para o benefício do próximo, diferentemente do que percebemos no momento atual da igreja em que o uso de fé restringe, exclusivamente, à busca pela própria satisfação.

A fé revelada pelo Espírito Santo nas escrituras não consiste na expectativa daquilo que eu quero que Deus faça por mim, mas na convicção daquilo que Deus tem a realizar em mim e sobretudo através de mim. Significa entender e amar a boa, agradável e perfeita vontade de Cristo. A Bíblia (1993, Hebreus, 11:24 à 26) declara que pela fé, Moisés, entendendo a vontade de Deus, preferiu ser maltratado junto ao seu povo do que fazer parte da família de Faraó, recusando possuir as riquezas do Egito e usufruir dos prazeres transitórios do pecado. Já o apóstolo Paulo traz o pronto consolo: "Porque para mim tenho por certo que os sofrimentos do tempo presente não podem ser comparados com a glória a ser revelada em nós" (BÍBLIA, Romanos, 8:18, grifo nosso).

Conforme demonstrado, a verdade descrita pela história da igreja no livro bíblico dos atos dos apóstolos esclarece que as grandes campanhas realizadas pela igreja primitiva não visavam o enriquecimento individual a partir da reivindicação de bênçãos particulares, mas a partilha coletiva proporcionada por uma fé relacional e um coração que cria. Sob essa perspectiva, demonstra-se um grande contrassenso devido à diferença financeira entre os grandes líderes religiosos e seus membros assalariados, pois, cada vez mais, templos luxuosos são construídos às custas de muitos membros 
que possuem casas miseráveis das quais pastores, bispos e apóstolos desfrutam de carrões, jatinhos particulares e iates às custas de muitos membros reféns de transportes públicos precários.

Entretanto, o grande paradoxo na teologia da prosperidade encontra-se entre a confissão positiva e a necessidade da entrega de ofertas ou "sacrifícios" em prol da obtenção de bênçãos, pois essa, geralmente, aguarda pelas finanças ou qualquer tipo de materialização da fé, e, assim, cabe destacar que ela se manifesta a partir do determinismo ou do poder da palavra falada. Se assim fosse, qual deveria ser o método correto para a obtenção das bênçãos: determinando com os lábios ou comprando com ofertas? De fato, nenhum dos dois extremos corresponde ao ensinamento bíblico, como apontam as reflexões. A Bíblia (1993, Atos, 4:10) registra que Pedro cheio do Espírito Santo, ao ser questionado sobre com que poder havia realizado a cura de um homem paralítico de nascença, declara que foi através do poder que há no nome de Jesus Cristo.

Em outro momento, a Bíblia (1993, Atos, 8:13 à 20) registra um episódio em que Simão havia sido batizado logo após ter abraçado a fé cristã. $E$, ao perceber que pela imposição das mãos dos apóstolos os dons do Espírito Santo eram concedidos aos que cressem, Simão oferece dinheiro como meio para obtenção dessa mesma autoridade. Então, Pedro o adverte declarando que a tentativa de obter o dom de Deus através do dinheiro serviria apenas para a sua própria perdição. Sendo assim, esses dois exemplos revelam de forma clara que o pensamento teológico dos primeiros discípulos, referente ao milagre da cura física, não estava condicionado à determinação exclusiva do desejo humano, mas à vontade e ao poder que há no nome de Jesus, de igual modo, a autoridade para a obtenção dos dons divinos não repousava sobre um preço que pudesse ser mensurado pelo dinheiro, mas sobre a exclusiva concessão do Espirito Santo segundo a sua multiforme graça.

\section{CONSIDERAÇÕES FINAIS}

$\mathrm{Na}$ Bíblia consta toda a fundamentação teológica e o amparo prático para a defesa da fé cristã. É fato que a validação das crenças e práticas da teologia da prosperidade 
encontram respaldo somente em experiências espirituais isoladas, não subsistindo quando confrontadas com as verdades bíblicas e as práticas comuns a igreja do Novo Testamento. Considerando as comparações apresentadas entre as igrejas primitiva e neopentecostal, mediante as questões que definem o tema da prosperidade bíblica, a conclusão lógica é que enquanto uma igreja se mobiliza em arrecadações, doações e partilhas e toma o poder que há no nome de Jesus para a realização de milagres em prol do seu próximo, a outra possui uma postura distinta, mais voltada às posses.

Articula-se a partir de campanhas, propósitos e sacrifícios interesseiros e intenta o usufruto de um determinismo egoísta que seria capaz de almejar apenas o benefício próprio. Absolutamente, a vida cristã não deve ser representada simplesmente por meio de um relacionamento superficial com Deus a base de trocas, em que são "sacrificadas" generosas importâncias à igreja visando a obtenção milagrosa de bens materiais, ou, ainda, a partir de motivações direcionadas a uma busca insaciável aos prazeres desse mundo, cuja felicidade passa a ser medida por todas essas vitórias conquistadas. A verdadeira vida em Cristo revela que a fé evangélica possibilita 0 alcance daquilo que Deus quer fazer no cristão e não simplesmente o que o cristão quer que Deus faça por ele.

\section{REFERÊNCIAS}

ARAÚJO, I. Dicionário do movimento pentecostal. Rio de Janeiro: CPAD, 2007.

BÍBLIA. A Bíblia Sagrada: Antigo e Novo Testamento. Tradução em português por João Ferreira de Almeida. Edição revista e atualizada no Brasil. $2^{\circ}$ ed. São Paulo: Sociedade Bíblia do Brasil, 1993.

CÉSAR, E. M. L. História da evangelização do Brasil: dos jesuítas aos neopentecostais. Viçosa: Ultimato, 2000.

GONDIM, R. O evangelho da Nova Era: uma análise e refutação bíblica da chamada Teologia da Prosperidade. São Paulo: Abba Press, 1993. 
GONZALEZ, J. L. Uma história do pensamento cristão. São Paulo: Cultura Cristã, 2004.

MARIANO, R. Os neopentecostais e a teologia da prosperidade. Novos Estudos, v. 44, n. 44, p. 24-44, 1996.

SILVA, V. G. da. Neopentecostalismo e religiões afro-brasileiras: Significados do ataque aos símbolos da herança religiosa africana no Brasil contemporâneo. Mana, v. 13, n. 1, p. 207-236, 2007.

\section{APÊNDICE - REFERÊNCIAS DE NOTA DE RODAPÉ}

2.

IBGE.

Disponível

em:

https://censo2010.ibge.gov.br/apps/atlas/pdf/Pag_203_Religi\%C3\%

A3o_Evang _miss\%C3\%A3o_Evang_pentecostal_Evang_nao\%20determinada_Diversidade\%20 cul-tural.pdf. Acesso em: 06 jun. 2019.

3. Universal. Disponível em: https://www.universal.org/a-universal/. Acesso em: 05 jun. 2019.

4. Ongrace. Disponível em: http://ongrace.com/portal/?historia=r-r-soares. Acesso em: 05 jun. 2019.

5. Universal. Disponível em: https://www.universal.org/a-universal/. Acesso em: 05 jun. 2019.

6.

Ancora.

Disponível

em:

http://www.revistaancora.com.br/revista_11/06\%20\%20\%20Silva\%

20e\%20Quitério.pdf. Acesso em: 06 jun. 2019.

7.

Renascer.

Disponível

em:

https://www.renasceremcristo.com.br/renascer/\#.XPf_jRZKjIU. Acesso em: 05 jun. 2019. 
8. Sara nossa Terra. Disponível em: https://saranossaterra.com.br/historia-da-sara/. Acesso em: 05 jun. 2019.

9. ROSAS. Disponível em: http://www.abhr.org.br/wp-content/uploads/2013/01/art_ ROSAS_neopentecostalismo.pdf. Acesso em: 05 jun. 2019.

10. IMPD. Disponível em: https://www.impd.org.br/milagres/2843. Acesso em: 11 jun. 2019.

11. IIGD. Disponível em: https://www.youtube.com/watch?v=fDwbHIBDJBg\&t=45s. Acesso em: 11 jun. 2019.

12. Ongrace. Disponível em: http://ongrace.com/portal/?historia=a-igreja-da-graca. Acesso em: 05 jun. 2019.

13. Ongrace. Disponível em: http://ongrace.com/portal/?testemunho=aprovacao-nafacul dade. Acesso em: 11 jun. 2019.

14. Universal. Disponível em: https://www.igrejauniversal.pt/determinei-o-valor-domeu-proprio-salario/. Acesso em: 10 jun. 2019.

15. Gospel Prime. Disponível em: https://www.gospelprime.com.br/pastor-silasmalafaia-res ponde-as-criticas-que-recebeu-sobre-a-oferta-de-r911/. Acesso em: 10 jun. 2019.

16. Ongrace. Disponível em: http://ongrace.com/portal/?testemunho=deixei-de-fumar. Acesso em: 10 jun. 2019.

17. Universal. Disponível em: https://www.universal.org/agenda/. Acesso em: 10 jun. 2019.

Enviado: Setembro, 2019.

Aprovado: Junho, 2020. 